\title{
CERAMICS
}

\section{Thermal behaviour of a zeolitic tuff}

\author{
Ö. Çağlar Duvarcı *, Y. Akdeniz, F. Özmıhçı, S. Ülkü, D. Balköse, M. Çiftçioğlu \\ Chemical Engineering Department, Faculty of Engineering, Izmir Institute of Technology, Gülbahçe Köyü, Urla, İzmir, Turkey \\ Received 7 January 2005; received in revised form 28 October 2005; accepted 16 January 2006 \\ Available online 18 April 2006
}

\begin{abstract}
Natural zeolites undergo structural changes after heating which open their possible use in different fields, related to their chemical and physical properties, such as building stone, lightweight aggregate, ceramic foam, concrete bricks, tiles, porcelain stoneware and additive in puzzolonic cements. In this study, thermal behavior of zeolitic tuff quarried from Gördes-Manisa, region of Turkey was investigated. Zeolitic rocks were first reduced to $2 \mu \mathrm{m}$ and pellets were prepared by dry-pressing. The pellets were heated for $30 \mathrm{~min}$ in the temperature range of $200-1200{ }^{\circ} \mathrm{C}$. Heating the tuff up to $600{ }^{\circ} \mathrm{C}$ did not cause any structural change detectable by X-Ray powder diffraction (X-Ray), Fourier Transform Infrared Spectroscopy (FTIR) and thermal characterization methods with regard to the original sample, while further increase in the temperature caused structural breakdown of zeolitic tuff. The appearance of the broad low intensity peaks in X-Ray diffraction diagrams indicated most probably a partial transformation of crystal structure into an amorphous structure. The Scanning Electron Microscopy (SEM) micrographs showed that the crystals seen in the original rock sample were broken during grinding and pressing processes. The crystal structure disappeared above $1000{ }^{\circ} \mathrm{C}$ and the spherical pores was observed at $1200{ }^{\circ} \mathrm{C}$. Chemical composition of the zeolitic tuff did not change significantly with respect to temperature. The highest density $\left(2.28 \mathrm{~g} / \mathrm{cm}^{3}\right)$ and hardness $(387 \mathrm{Hv})$ were obtained by sintering the pellets at $1000{ }^{\circ} \mathrm{C}$ for $30 \mathrm{~min}$.
\end{abstract}

(C) 2006 Elsevier Ltd and Techna Group S.r.l. All rights reserved.

Keywords: Zeolitic tuff; Characterization; Heat treatment; X-Ray; SEM

\section{Introduction}

Zeolites are crystalline aluminosilicates of groups IA and IIA elements such as sodium, potassium, barium, magnesium and calcium [1]. Zeolites possessing a high $\mathrm{SiO}_{2} / \mathrm{Al}_{2} \mathrm{O}_{3}$ ratio and three-dimensional (3D) systems of large pore channels are of technological interest. They combine a high thermal and hydrothermal stability with a high resistance to pore blockage [2]. Many studies reported on the structural evolution of zeolites when they were heat-treated. These studies mostly focused on the preparation of aluminosilicate ceramics by using synthetic zeolites as a starting precursor. It is also mentioned by Breck [1] that natural zeolite can be an alternative material to synthetic zeolite. But, the composition and properties of natural zeolites vary significantly from sample to sample. Before using a zeolitic tuff for a certain application its thermal and structural properties should be carefully investigated. Natural zeolites have voids and channels which are typically in the range of molecular dimensions, i.e. 3-10 ̊. The density of natural

\footnotetext{
* Corresponding author. Tel.: +90 232750 6325; fax: +90 2327506196.

E-mail address: ozlemduvarci@iyte.edu.tr (Ö. Ç. Duvarcı).
}

zeolites ranged between 2 and $2.3 \mathrm{~g} / \mathrm{cm}^{3}$ and $\mathrm{SiO}_{2} / \mathrm{Al}_{2} \mathrm{O}_{3}$ ratio generally lies in the range of 4.25-5.25 [1].

Effects of heat treatment on properties of zeolites have been investigated by different researchers. Microstructural changes, porosity evolution and properties of cordierite-based composites on heating have been studied by Tulyaganov et al. [3]. The aluminosilicate-based ceramics were produced in the composition of alkaline-earth-aluminosilicate glass powder, kaolin, alumina and magnesite. Sintering temperature of the samples were in the range of $900-1410{ }^{\circ} \mathrm{C}$. The maximum density was found as $2.375 \mathrm{~g} / \mathrm{cm}^{3}$ at $1350{ }^{\circ} \mathrm{C}$. They have also noticed a selfglazing effect in the samples after sintering.

Modified and unmodified zeolite can act as precursors for a variety of aluminosilicate ceramics. Some advantages have been reported for ceramic preparation compared to the traditional methods of mixing oxides. Monolithic anorthite, anorthite-cordierite, or cordierite-based ceramics were prepared from calcium, calcium-magnesium or magnesium ion exchange zeolite, respectively [4].

According to Chandrasekhar and Pramada [5] apparent density of the heated products (Ca low silica zeolite) closely agree with the liquid water absorption; the samples with lower density absorb more liquid water. Zeolites heated at $750{ }^{\circ} \mathrm{C}$ 
show lower density compared with the zeolites heated at $850{ }^{\circ} \mathrm{C}$. Samples heated at $950,1050,1150{ }^{\circ} \mathrm{C}$ have almost similar densities. Ca zeolites highest density is found as $1.7 \mathrm{~g} /$ $\mathrm{cm}^{3}$ at $850{ }^{\circ} \mathrm{C}$. The scanning electron micrographs of the sample sintered at $950{ }^{\circ} \mathrm{C}$ clearly show that the glass formation was taking place with a much lower number of pores compared to the corresponding products fired at higher rate [5].

Dondi et al. investigated the use of natural zeolites in ceramic tiles because natural zeolites were promising substitutes for feldspathic fluxes in ceramic bodies [6]. Their further investigation had covered the influence of zeolites on sintering and technological properties of porcelain stoneware tiles [7]. Dondi et al. had also studied on the lightweight aggregates $\left(0.5-0.7 \mathrm{~g} / \mathrm{cm}^{3}\right)$ from zeolitic tuff which was directly put into the heated furnace at $1350-1500{ }^{\circ} \mathrm{C}$ for $2-$ $5 \mathrm{~min}$. They investigated both the expansion at high temperature and the technological features of fired products. It was mentioned that the firing expansion of the zeolitic tuff mainly depends on the chemical composition and water content [8].

Arcoya et al. had studied the physicochemical and catalytic properties of a modified natural clinoptilolite. They studied the thermal stability of the calcined natural zeolite at 600, 700 and $800{ }^{\circ} \mathrm{C}$ with a heating rate of $5{ }^{\circ} \mathrm{C} / \mathrm{min}$ using XRD analysis. They reported that XRD pattern of the starting material shows high crystallinity and characteristic lines of clinoptilolite are observed at $2 \theta$ values of $9.92,22.43$ and $30.50^{\circ}$. A partial breakdown of the structure took place at $600{ }^{\circ} \mathrm{C}$ [9].

Goryainov et al. studied the quantitative determination of clinoptilolite by IR spectroscopy using wet grinding and dry homogenized zeolite rocks [10]. Fuentes et al. studied the IR vibrations of natural zeolite. They considered two groups of frequencies for the vibrations in all zeolites. Internal vibrations of $\mathrm{T}-\mathrm{O}$ and vibrations of external linkages between tetrahedra and the internal vibrations $\mathrm{T}-\mathrm{O}$ are sensitive to the $\mathrm{SiO}_{2} / \mathrm{Al}_{2} \mathrm{O}_{3}$ ratio of the framework, where $\mathrm{T}$ represents aluminum or silicon and $\mathrm{O}$ represents the oxygen atom. The internal $\mathrm{T}-\mathrm{O}$ stretching mode is at $650-820 \mathrm{~cm}^{-1}$. Sensitive and internal T-O bonding vibration is $420-500 \mathrm{~cm}^{-1}$ [11].

Esenli and Kumbasar studied the thermal behavior of natural zeolite of Western Anatolian. Natural zeolite showed two endotherms at about 120 and $750{ }^{\circ} \mathrm{C}$ in Differential Thermal
Analysis (DTA). These two peaks belonged to water loss and destruction of natural zeolite, respectively. Thermal Gravimetric Analysis (TGA) showed that the total amount of water loss below $800{ }^{\circ} \mathrm{C}$ was about $14.50 \%$ [12].

Many physical and chemical changes could occur simultaneously during heating of zeolites. Volatilization of water vapor from the system and de-alumination of zeolitic structure are probable processes that will occur on heating. Collapse of the microporous structure of zeolite, melting of product which has lower melting point and entrapment of gaseous products are some of these phenomena.

The primary objective of this study is to investigate the microstructural development of a well-characterized zeolitic tuff during heat treatment. The determination of heat treatment conditions for maximum density and hardness are aimed as well as for lightweight aggregate formation.

Zeolitic tuff from Western Anatolia Gördes Turkey was characterized by Inductively Coupled Plasma with Atomic Emission Spectroscopy (ICP-AES) and X-Ray powder diffraction (X-Ray). It was ground and fractionated to $2 \mu \mathrm{m}$ particle size and formed into pellets. Effect of heating up to $1200{ }^{\circ} \mathrm{C}$ on the properties of the pellets were investigated by Fourier Transform Infrared Spectroscopy (FTIR), Thermal Gravimetric Analysis, Differential Thermal Analysis, Scanning Electron Microscopy (SEM), density $(\rho)$, hardness (Vicker's Hardness) and color measurements $(L, a, b)$.

\section{Experimental procedure and characterization techniques}

Samples in light green color were taken from GördesManisa, Aegean region of Turkey. The skeleton density of the tuff was measured by helium pycnometer [Ultrapycnometer 1000, Quantochrome]. The chemical composition of the zeolitic tuff was determined using Inductively Coupled Plasma Atomic Emission Spectroscopy (ICP-AES 96, Varian) and Energy Dispersive X-Ray Spectroscopy (EDX), which are given in Table 1. The fracture surfaces of the heated samples were used for EDX analyses. Zeolitic tuff pieces were ground and fractionated to $45 \mu \mathrm{m}$ by sieving, then were placed into Multifix Ball Mill. The $50 \%$ of the ceramic bottle was filled with zirconia balls with a mixture of $59.8 \%$ the powder and

Table 1

Chemical composition of the zeolitic tuff taken from Gördes-Manisa, the region of Aegion, Turkey

\begin{tabular}{|c|c|c|c|c|c|c|c|c|}
\hline \multirow[t]{2}{*}{ Elements wt $\%$} & \multirow[t]{2}{*}{ ICP original } & \multicolumn{7}{|l|}{ EDX } \\
\hline & & Original & $700{ }^{\circ} \mathrm{C}$ & $800{ }^{\circ} \mathrm{C}$ & $900{ }^{\circ} \mathrm{C}$ & $1000{ }^{\circ} \mathrm{C}$ & $1100^{\circ} \mathrm{C}$ & $1200^{\circ} \mathrm{C}$ \\
\hline $\mathrm{Na}_{2} \mathrm{O}$ & 1.9 & 1.5 & 1.8 & 1.7 & 1.7 & 1.7 & 1.6 & 1.4 \\
\hline $\mathrm{MgO}$ & 1.1 & 1.3 & 1.6 & 1.7 & 1.4 & 1.3 & 0.9 & 0.9 \\
\hline $\mathrm{Al}_{2} \mathrm{O}_{3}$ & 13.6 & 13.4 & 13.5 & 13.6 & 13.5 & 13.9 & 13.6 & 14.1 \\
\hline $\mathrm{SiO}_{2}$ & 75.4 & 76.3 & 75.9 & 74.8 & 75.6 & 75.9 & 74.9 & 74.5 \\
\hline $\mathrm{K}_{2} \mathrm{O}$ & 4 & 3.3 & 3.2 & 3.6 & 3.3 & 2.9 & 3.4 & 4.4 \\
\hline $\mathrm{CaO}$ & 2.2 & 2.1 & 2.0 & 2.6 & 2.0 & 1.9 & 2.6 & 2.7 \\
\hline $\mathrm{Fe}_{2} \mathrm{O}_{3}$ & 1.8 & 2.1 & 2.0 & 2.0 & 2.5 & 2.4 & 2.0 & 1.8 \\
\hline Total & 100.0 & 100.0 & 100.0 & 100.0 & 100.0 & 100.0 & 100.0 & 100.0 \\
\hline $\mathrm{SiO}_{2} / \mathrm{Al}_{2} \mathrm{O}_{3}$ & 5.5 & 5.7 & 5.6 & 5.5 & 5.6 & 5.5 & 5.5 & 5.3 \\
\hline
\end{tabular}


$0.15 \%$ polyethylene glycol (PEG 4000) and ethanol on weight basis. The size fractionation of the ball-milled powder was done by sedimentation. The final particle size of the zeolitic tuff was $2 \mu \mathrm{m}$. The powder was dry-pressed to form pellets in about $1 \mathrm{~mm}$ thickness and $10 \mathrm{~mm}$ diameter by using stainless steel die by applying pressure of $304 \mathrm{MPa}$ at $25{ }^{\circ} \mathrm{C}$. The sintering process of the pellets were performed in a chamber furnace (Carbolite 1600 RHF 16/3c) and heated to 700, 800, 900, 1000, 1100 and $1200{ }^{\circ} \mathrm{C}$ with a heating rate of $10{ }^{\circ} \mathrm{C} / \mathrm{min}$ and by a soaking time of $30 \mathrm{~min}$. Pellets were also heated at $200-600{ }^{\circ} \mathrm{C}$ range for $30 \mathrm{~min}$ for FTIR analyses. Weights of the pellets were measured before and after sintering process in order to determine mass loss of the pellets. Their appearance was inspected by bare eye and their color was measured in terms of " $L, a, b$ " values using Avantes AvaMouse handheld reflection spectrometer. The pellets were inspected by eye whether they are dull or shining. Fourier Transform Infrared (Shimadzu 8601PC) Spectroscopy was used for structural characterization of zeolite. Thermal Gravimetric Analyzer (TGA-51, Shimadzu) and Differential Thermal Analyzer (DTA-50, Shimadzu) were used to study the thermal behavior of the zeolitic tuff $\left(1000{ }^{\circ} \mathrm{C}\right.$ for DTA and TGA at a heating rate of $10{ }^{\circ} \mathrm{C} / \mathrm{min}$ under $\mathrm{N}_{2}$ atmosphere with the flow rate of $40 \mathrm{ml} / \mathrm{min}$ ). X-Ray powder diffraction patterns were obtained to determine the crystal structure and structural properties. The samples prepared by grinding the heated pellets in acetone media by using an agate mortar. X-Ray diffraction patterns were recorded on a Philips $\mathrm{X} /$ Pert X-Ray Diffractometer with Ni filtered $\mathrm{Cu} \mathrm{K} \alpha$ radiation in the range of $2 \theta$ values $5-40^{\circ}$. The influence of pressing and heat treatment on the morphology of the zeolitic tuff was observed by scanning electron microscope (SEM, Philips XL 305). The density measurement of the heated pellets was carried out by using Archimedes Principle. Vickers Microhardness Tester (HVS-1000) was used to measure the microhardness of the sintered pellets after mounting and polishing processes. All analyses except TGA and DTA were performed at room temperature.

\section{Results and discussion}

\subsection{Chemical composition of zeolitic tuff and the effect of temperature}

EDX and ICP-AES were used to obtain chemical composition of zeolitic tuff. While the bulk chemical analysis was obtained by ICP-AES, EDX gave information about the chemical composition of the fracture surfaces. As seen in Table 1, comparable results were observed for both $\mathrm{SiO}_{2}$ and $\mathrm{Al}_{2} \mathrm{O}_{3}$ contents by EDX and by ICP-AES analysis. The differences in ICP-AES and EDX analyses were 1.06 and $1.49 \%$ for $\mathrm{SiO}_{2}$ and $\mathrm{A}_{2} \mathrm{O}_{3}$, respectively.

In overall glance, surface chemical composition slightly changes with respect to temperature up to $1200{ }^{\circ} \mathrm{C}$. $\mathrm{SiO}_{2} / \mathrm{Al}_{2} \mathrm{O}_{3}$ ratios of the samples were about 5.5. The presence of elements having smaller concentrations than $\mathrm{Al}$ and $\mathrm{Si}$ were observed and reported in oxide form. For example, Fe element was also present and it was reported as $\mathrm{Fe}_{2} \mathrm{O}_{3}$.
Table 2

The $L, a, b$ values with respect to white, color and appearance of unheated and heated pellets of zeolitic tuff

\begin{tabular}{rlrrll}
\hline Temperature $\left({ }^{\circ} \mathrm{C}\right)$ & $L$ & \multicolumn{1}{l}{$a$} & \multicolumn{1}{l}{$b$} & Color & Appearance \\
\hline 25 & 85.93 & -0.81 & 7.78 & Light green & Dull \\
700 & 76.58 & 4.38 & 16.57 & Pink & Dull \\
800 & 74.24 & 6.83 & 20.68 & Dark pink & Dull \\
900 & 71.79 & 10.08 & 27.77 & Light brown & Dull \\
1000 & 44.55 & 16.37 & 29.02 & Dark brown & Shining \\
1100 & 52.26 & 16.60 & 32.14 & Light gray & Shining \\
1200 & 62.03 & 3.96 & 18.74 & Light gray & Shining \\
\hline
\end{tabular}

Gennaro et al. reported that the high $\mathrm{Fe}_{2} \mathrm{O}_{3}$ content promotes a darkening of color [7]. Similarly, the color change of the pellets from light green to dark brown at temperatures between 700 and $1000{ }^{\circ} \mathrm{C}$ was observed. The possible reason would be iron element initially present was in oxidation state II and it was oxidized to state III by heating. Also, the color of the pellets was quantified by measuring $L, a, b$ values reported in Table 2 . Decreasing " $L$ " values from 85.93 to 44.55 by heating up to $1000{ }^{\circ} \mathrm{C}$ confirmed the darkening of the color of the pellets. However, the " $L$ " value increased to 62.03 by further heating up to $1200{ }^{\circ} \mathrm{C}$ since the color changed to light gray.

\subsection{Effect of heat treatment on crystal structure}

X-Ray patterns of the zeolitic tuff samples were analyzed considering the peaks within the 10 and $40^{\circ} 2 \theta$ range. The characteristic peaks of clinoptilolite at $2 \theta$ values of 9.92, 22.43, $25.8,30.05$ and $32^{\circ}$ were observed in the X-Ray diagram of the sample in Fig. 1 [9]. In addition to zeolitic phase $(80 \%)$ presence of quartz, cristobalite and K-feldspar was reported for the same zeolitic tuff [13]. Heating up to $800{ }^{\circ} \mathrm{C}$ does not produce any structural changes detectable by X-Ray with regard to the original sample, while further increase in the temperature produces decrease in main peaks of clinoptilolite. Finally, the disappearance of the characteristic peaks of clinoptilolite was observed with further increase in temperature, which indicates the transformation of zeolite into an amorphous phase. On the other hand, both the original and the heated samples contained $\mathrm{SiO}_{2}$ as a crystalline phase, which did

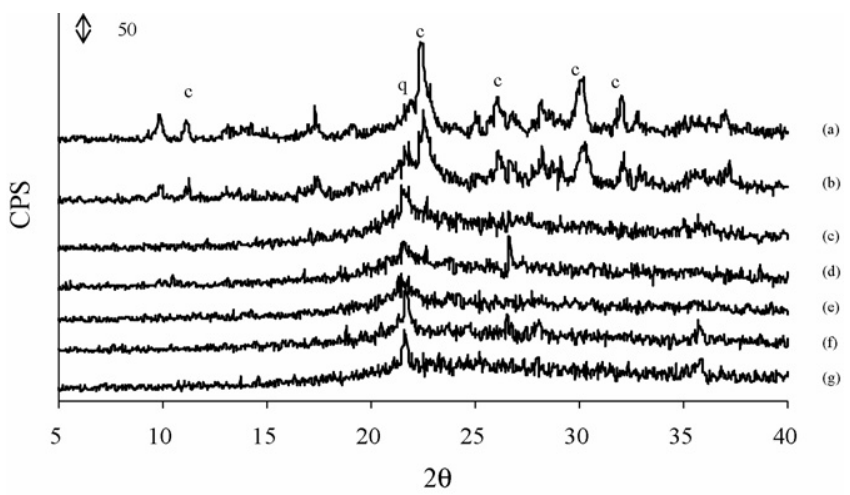

Fig. 1. The XRD diffraction patterns of zeolitic tuffs: (a) unheated sample; heat-treated samples at (b) $700{ }^{\circ} \mathrm{C}$; (c) $800{ }^{\circ} \mathrm{C}$; (d) $900{ }^{\circ} \mathrm{C}$; (e) $1000{ }^{\circ} \mathrm{C}$; (f) $1100{ }^{\circ} \mathrm{C} ;(\mathrm{g}) 1200{ }^{\circ} \mathrm{C}$ (c: clinoptilolite, q: quartz). 


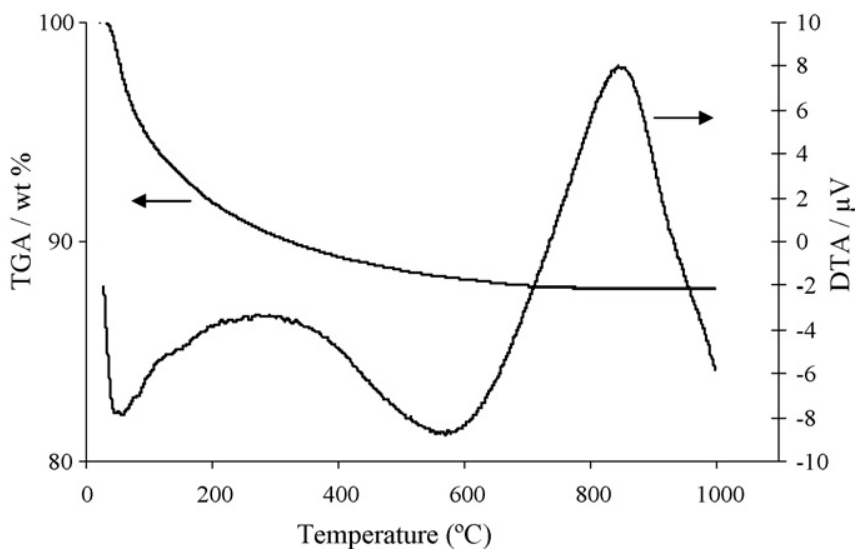

Fig. 2. (a) TGA; (b) DTA curves of zeolitic tuff.

not change by heating, indicated by the peak at $2 \theta$ value of $21.8^{\circ}$ [9].

\subsection{Thermal behavior of zeolitic tuff}

Thermal behavior of zeolitic tuff was investigated by using TGA and DTA. The curves are given in Fig. 2. The TGA of the zeolitic tuff showed $11.5 \%$ weight loss up to $1000{ }^{\circ} \mathrm{C}$. TGA curves were examined using the procedure outlined by Knowlton and White [14] for the temperature ranges 25-85, 85-285 and $285-1000{ }^{\circ} \mathrm{C}$ corresponding to external, loosely bound and tightly bound water, respectively. The weight losses were found as $4.10,4.41$ and $2.99 \%$ by weight for the external, loosely and tightly bound water for the examined zeolitic tuff. The DTA pattern of the zeolitic tuff shows dehydration of zeolitic water until $600{ }^{\circ} \mathrm{C}$ and above $600{ }^{\circ} \mathrm{C}$ a broad endothermic peak was observed, which gives information on the structural breakdown. These results were confirmed with FTIR results.

\subsection{Study of heat treatment effect on zeolitic tuff by FTIR}

The structural information of the zeolitic tuff was obtained by FTIR spectroscopy. Peaks related with isolated and $\mathrm{H}$-bonded $\mathrm{O}-\mathrm{H}$ stretching at 3700 and $3400 \mathrm{~cm}^{-1}$, respectively, and $\mathrm{H}_{2} \mathrm{O}$

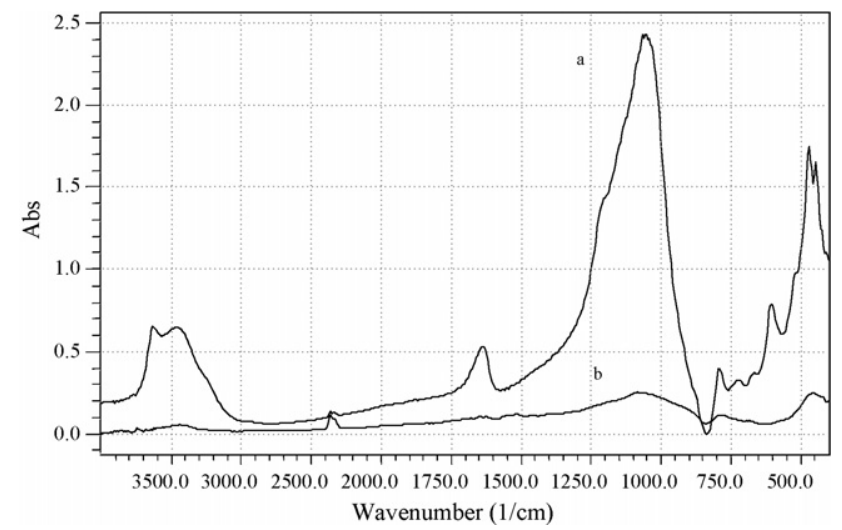

Fig. 3. The FTIR spectrum of zeolitic tuff (a) at $25^{\circ} \mathrm{C}$ and (b) heat-treated at $1200{ }^{\circ} \mathrm{C}$.

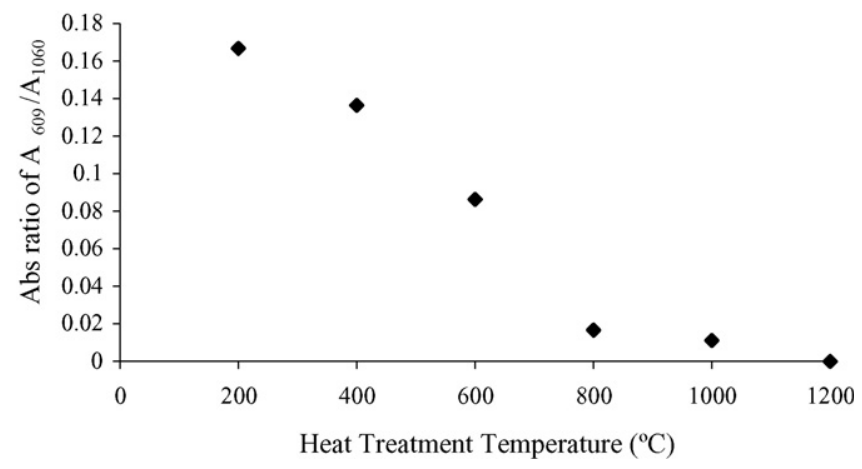

Fig. 4. Change of the ratio of Absorbances (Abs) at $609 / 1060 \mathrm{~cm}^{-1}$ bands with respect to heat treatment temperature.

bending at $1620 \mathrm{~cm}^{-1}, \mathrm{~T}-\mathrm{O}$ stretching at $1060 \mathrm{~cm}^{-1}$, external T$\mathrm{O}$ at $790 \mathrm{~cm}^{-1}$ and external and internal double-ring vibrations at $609 \mathrm{~cm}^{-1}$ were present in the IR spectrum of zeolitic tuff at $25^{\circ} \mathrm{C}$ in Fig. 3. The peaks at 1060, 790 and $609 \mathrm{~cm}^{-1}$ were the characteristic peaks of clinoptilolite $[10,11,15]$. The Absorbance (Abs) at $609 \mathrm{~cm}^{-1}$ is the characteristic peak related with the

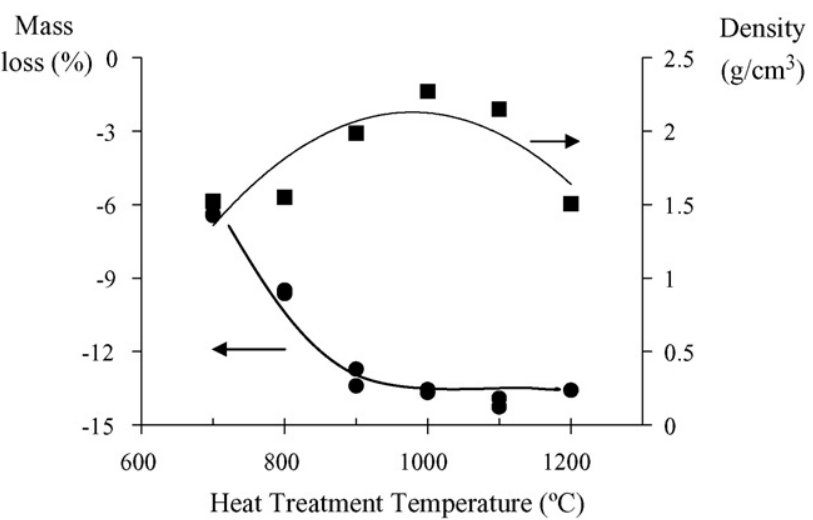

Fig. 5. The change in density and mass loss with respect to heat treatment temperature.

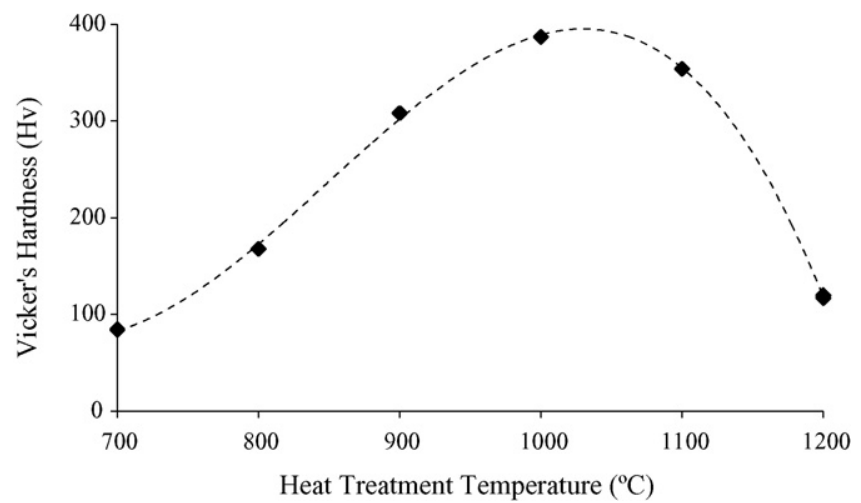

Fig. 6. The change in Vicker's Hardness of pellets with respect to heat treatment temperature. 
amount of clinoptilolite structure present in the zeolitic tuff. Increasing temperature to $1200{ }^{\circ} \mathrm{C}$ caused the structural breakdown of the zeolitic tuff and the disappearance of the characteristic peaks, which is shown in Fig. 3.

The change in the absorbance ratio of $609-1060 \mathrm{~cm}^{-1}$ band with the increasing temperature is given in Fig. 4 This indicated that until $600{ }^{\circ} \mathrm{C}, 609 \mathrm{~cm}^{-1}$ bands were present but above this temperature the ratio of $609-1060 \mathrm{~cm}^{-1}$ band decreased and disappeared at $800{ }^{\circ} \mathrm{C}$. It showed that the structure of clinoptilolite collapsed at $800{ }^{\circ} \mathrm{C}$.

Moreover, the distortion of framework was observed by the shift of $\mathrm{T}-\mathrm{O}$ stretching at $1060 \mathrm{~cm}^{-1}$ band in mid-infrared region. Increasing temperature from 25 to $1200{ }^{\circ} \mathrm{C}$ resulted in shift of 1060 towards $1080 \mathrm{~cm}^{-1}$ which indicated decrease in Al content in framework $[1,11]$.

\subsection{Densification of heated pellets}

The densification and mass loss behavior of pellets with respect to heating temperature are given in Fig. 5. The densities of the pellets increased by heating up the $1000{ }^{\circ} \mathrm{C}$ to about $2.28 \mathrm{~g} / \mathrm{cm}^{3}$. Above $1000{ }^{\circ} \mathrm{C}$ the density of the pellets showed a decreasing trend due to volume expansion. The volume expansion was not related to mass loss since the mass of the
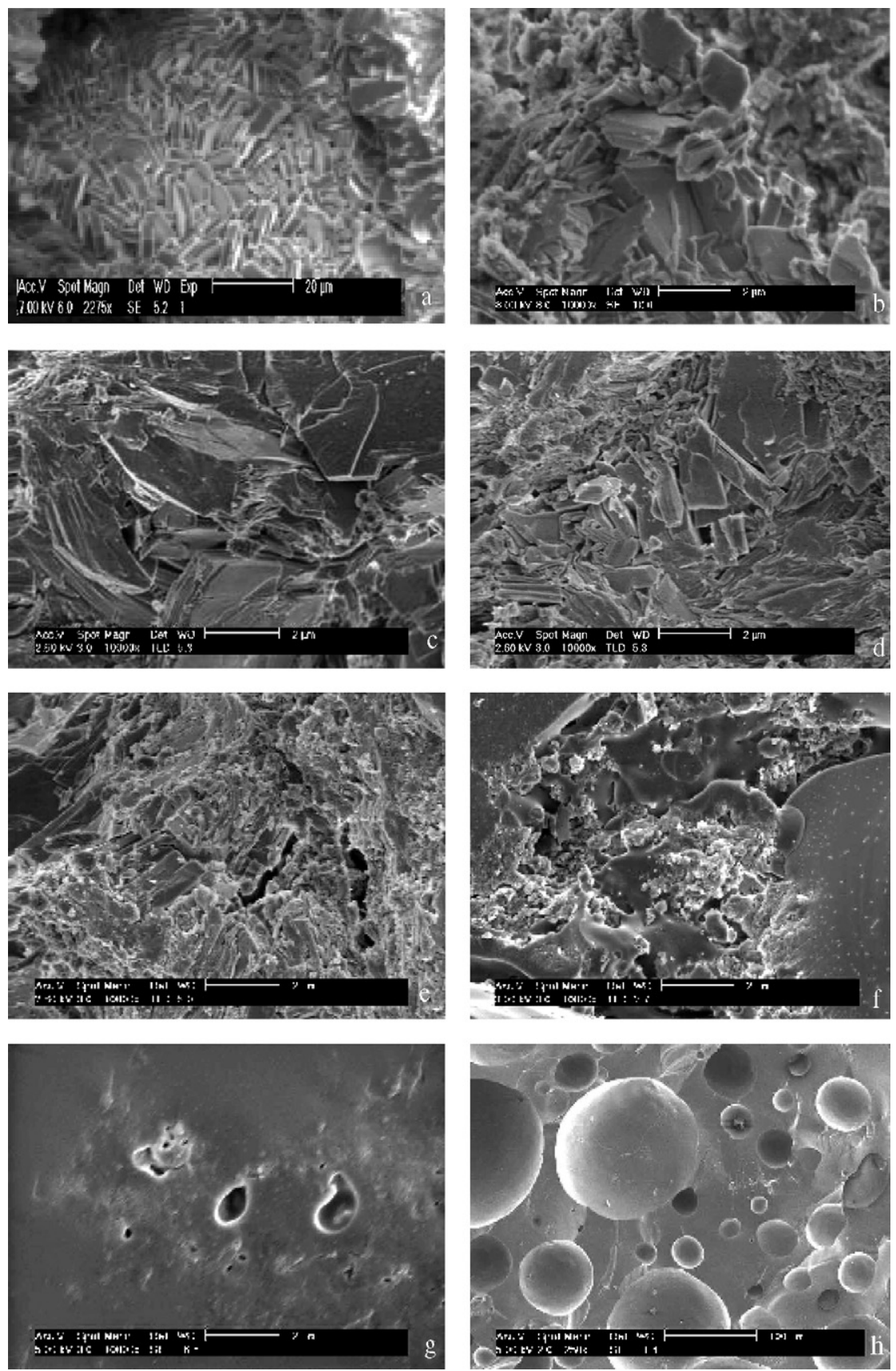

Fig. 7. The SEM micrographs of zeolitic samples in (a) rock form; (b) pellet form; pellets heated at (c) $700{ }^{\circ} \mathrm{C}$; (d) $800{ }^{\circ} \mathrm{C}$; (e) $900{ }^{\circ} \mathrm{C}$; (f) $1000{ }^{\circ} \mathrm{C}$; (g) $1100{ }^{\circ} \mathrm{C}$; and (h) $1200{ }^{\circ} \mathrm{C}$ 
pellets decreased up to $1000{ }^{\circ} \mathrm{C}$ and did not change with further heating to higher temperatures.

Above $1000{ }^{\circ} \mathrm{C}$, while the mass of pellets was constant, the diameter and thickness of pellets increased due to volume expansion. The maximum density obtained at $1000{ }^{\circ} \mathrm{C}(2.28 \mathrm{~g} /$ $\mathrm{cm}^{3}$ ) was still lower than the measured skeleton density value $\left(2.4 \mathrm{~g} / \mathrm{cm}^{3}\right)$ of zeolitic tuff and it is comparable to the value of $2.375 \mathrm{~g} / \mathrm{cm}^{3}$ for aluminum silicate based ceramics sintered at $1350{ }^{\circ} \mathrm{C}$ which was observed by Tulyaganov et al. [3]. A strong self-glazing effect above $1000{ }^{\circ} \mathrm{C}$ was observed. The appearance of the samples changed from a dull to shining as seen in Table 2. Further increase in temperature caused deformation of the shape of pellets and decrease in density because of formation of pores. Similar observations were also made by Tulyaganov et al. when sintering was done at $1300{ }^{\circ} \mathrm{C}$ and by Dondi et al. when the Italian zeolitic tuff was directly put into $1350{ }^{\circ} \mathrm{C}$ heated furnace $[3,8]$.

The hardness test of the pellets by Vicker's Hardness Tester showed the hardness increased from 75 to $387 \mathrm{Hv}$ by heating from 700 to $1000{ }^{\circ} \mathrm{C}$ (Fig. 6). Further heating caused decrease of the hardness to $135 \mathrm{Hv}$ due to volume expansion.

\subsection{Effect of sintering on morphology}

The SEM micrographs of the original and heated pellets are given in Fig. 7. The first two ( $a$ and b) SEM micrographs belonged to the original rock and pellet forms of unheated zeolites, respectively. While the original rock had 10-15 $\mu \mathrm{m}$ sized crystals, the pellet form had particles with average size of $1.5-2 \mu \mathrm{m}$. This indicated efficiency of the grinding and size separation below $2 \mu \mathrm{m}$ process by sedimentation. The crystals in the structure seem to be deformed in pellets due to the ball milling and/or dry-pressing steps of the pellet formation. The crystals were still present in the samples heated until $1000{ }^{\circ} \mathrm{C}$ but they were not exactly in the same form seen in the original rock sample.

At $1200{ }^{\circ} \mathrm{C}$, porous structure was observed in corresponding SEM micrograph. The first possible reason for the formation of porous structure might be due to entrapment of vapor derived from the volatilization. The second possible reason might be due to the decomposition of any thermally unstable material and/or the water vapor present in the zeolitic tuff.

The derived vapor partially trapped by viscous body may cause the formation of pores, which leads to decrease in density and the deformation of pellets. The pores were closed and distributed homogeneously. Further increase in sintering temperature caused an increase in the size and number of the pores. The average diameter of the pores at $1000{ }^{\circ} \mathrm{C}$ was $18.8 \mu \mathrm{m}$, (varied between 8 and $30 \mu \mathrm{m}$ ) and at $1200{ }^{\circ} \mathrm{C}$ was $96 \mu \mathrm{m}$, (varied between 8 and $240 \mu \mathrm{m}$ ). Similar porous structure were observed for $\mathrm{Ca}$-zeolite by Chandrasekhar and Pramada, [5] and cordierite based ceramics from alkalineearth-aluminosilicate by Tulyaganov et al. [3]. Dondi et al. used this feature for the production of lightweight aggregates from Italian zeolitic tuff. Their conclusion on the expansion of the zeolitic tuff was the occurrence of thermally unstable gas releasing phases, water vapor derived from dehydration and secondarily the presence smectite, opal and volcanic glass in their investigated materials. They concluded that to get lightweight aggregates having densities between 0.5 and $0.7 \mathrm{~g} / \mathrm{cm}^{3}$, the samples having a silica-alumina ratio in 4-5.6 should be used [8]. In the present study, pellets having $1.5 \mathrm{~g} / \mathrm{cm}^{3}$ density were obtained at $1200{ }^{\circ} \mathrm{C}$ while the silicaalumina ratio was around 5.5 . The slow heating rate $\left(10{ }^{\circ} \mathrm{C} /\right.$ min) and longer soaking time (30 min) might be the reasons for obtaining higher densities compared to the study of Dondi et al.

\section{Conclusion}

Heat treatment effect on zeolitic tuff mainly containing clinoptilolite was investigated. The heat treatment conditions for maximum density and hardness were determined. The original structure unchanged up to $800{ }^{\circ} \mathrm{C}$ hence the zeolitic tuff can be used for applications at moderate temperatures. Further heating caused complex structural transformations occurring with breakdown of the three-dimensional network structure of the zeolitic tuff. The hardness of the pellets increased considerably by heating from 700 to $1000{ }^{\circ} \mathrm{C}$. However, further heating lowers the values of hardness and density but increases the size and number of the pores. The formation of porous structure might be due to volatilization and decomposition of any thermally unstable material and/or the water vapor present in the zeolitic tuff. However, the size and number of the pores in pellets sintered at $1200{ }^{\circ} \mathrm{C}$ were much more than expected while comparing the factors of heating processes in literature such as heating rate, soaking time and sintering temperature. Hence, higher heating rates may cause larger expansion of pellets due to a rapid derivation of gases. By using this feature, zeolitic tuffs might be used in the production of lightweight aggregates and concrete bricks and also as an alternative source of substitute material in ceramic industry considering both its low cost and simple processing. The heat treatment process needs to be adjusted for the type of the application. Production of dense materials from zeolitic tuff requires a slow heat treatment process in the contrary of production of materials having densities lower than water. Also, color change by heat treatment should be taken into consideration for the selection of the application area.

\section{Acknowledgement}

The authors express their thanks to Turkish Government Planning Organization which supported this project with project number IYTE 96K121240.

\section{References}

[1] D.W. Breck, Zeolite Molecular Sieve; Structure, Chemistry And Use, John Wiley and Sons, New York, 1974.

[2] M.A. Camblor, P.A. Barrnett, M.-J. Diaz-Cabanas, L.A. Villaescusa, M. Puche, T. Boix, E. Perez, H. Koller, High silica zeolites with threedimensional systems of large pore channels, Mesoporous Mater. 48 (2001) 11-22. 
[3] D.U. Tulyaganov, M.E. Tukhtaev, J.I. Escalante, M.J. Ribeiro, J.A. Labrincha, Processing of coerdierite based ceramics from alkalineearth-aluminosilicate glass, kaolin, alumina and magnesite, J. Eur. Ceram. Soc. 22 (2002) 1775-1782.

[4] S. Chandrasekhar, P.N. Pramada, Sintering behaviour of ammonium exchanged low silica zeolites synthesised by two different routes, Ceram. Int. 27 (3) (2001) 351-361.

[5] S. Chandrasekhar, P.N. Pramada, Sintering behaviour of calcium exchanged low silica zeolites synthesized from kaolin, Ceram. Int. 27 (1) (2001) 105-114.

[6] M. Dondi, M. de Gennaro, R. de Gennaro, P. Cappelletti, G. Cerri, G. Guarini, A. Langella, D. Naimo, Natural zeolites in ceramic tiles: prospects and limits, in: Proceedings 10th CIMTEC, International Ceramic Congress, Florence, 2002.

[7] R. de Gennaro, P. Cappelletti, G. Cerri, M. de Gennaro, M. Dondi, G. Guarini, A. Langella, D. Naimo, Influence of zeolites on the sintering and technological properties of porcelain stoneware tiles, J. Eur. Ceram. Soc. 23 (2003) 2237-2245.

[8] M. Dondi, P. Cappelletti, G. Cerri, M. de Gennaro, R. de Gennaro, A. Langella, Zeolitc tuffs as raw materials for lightweight aggregates, Appl. Clay Sci. 25 (2004) 71-81.
[9] A. Arcoya, J.A. Gonzalez, G. Label, X.L. Seona, N. Travieso, Role of the counterions on the molecular sieve properties of a clinoptilolite, Microporus Mater. 7 (1996) 1-13.

[10] S.V. Goryainov, V.N. Stolpovskaya, A.Yu. Likhacheva, I.A. Belitsky, B.A. Fursenko, Quantitative determination of clinoptilolite and heulandite in tuffaceous deposits by infrared spectroscopy, in: D.W. Ming, F.A. Mumpton (Eds.), Proceedings International Conference, Zeolite'93, Brockport, New York, (1995), pp. 196-201.

[11] R. Fuentes, R. Salvador, M. Mir, O. Picozo, G. Quintana, M. Delgado, Thermal and cation influence on IR vibrations of modified natural clinoptilolite, Microporous Mesoporous Mater. 20 (1998) 269-281.

[12] F. Esenli, I. Kumbasar, Thermal Behavior of Heulandites and Clinoptilolites of Western Anatolia, Zeolites and Related Microporous Materials, State of the Art, vol. 84, 1994, pp. 645-651.

[13] A. Top, S. Ülkü, Silver, zinc, and copper exchange in a Na-clinoptilolite and resulting effect on antibacterial activity, Appl. Clay Sci. 27 (2004) 13-19.

[14] G.D. Knowlton, T.R. White, Thermal study of types of water associated with clinoptilolite, Clays Clay Miner. 29 (5) (1981) 404-411.

[15] G.V. Tsitsishvilli, T.G. Andronikashvilli, L.D. Filizova, G.N. Kırov, Natural Zeolites, Ellis Horwood Limited, England, 1992. 